\title{
ENSINAR A FRONTEIRA - UMA INTRODUÇÃO
}

\author{
ADRIANA DORFMAN \\ Professora da UFRGS \\ adriana.dorfman@ufrgs.br \\ ROBERTO FILIZOLA \\ Professor da UFPR \\ robertofilizola@gmail.com \\ JULIAN MOKWA FÉLIX \\ Bacharel em Relações Internacionais \\ julianmfx@gmail.com
}

Os mapas políticos estão presentes nas escolas desde sempre, e evocam para um sem número de pessoas imagens sobre seus tempos de estudantes. Essa memória guarda sentidos diversos atribuídos ao mapa pelos sujeitos que direta ou indiretamente são afetados por esse objeto da materialidade escolar. Sim, o mapa é um objeto da cultura material escolar, assim como o mobiliário, a biblioteca ou os uniformes. Nessa perspectiva, os mapas revelam muito mais do que a distribuição espacial dos objetos geográficos, termo aqui emprestado de Milton Santos (1996), pois possibilitam desvelar modos de conceber o ensino de Geografia e História. Para além de sua imagem, aparentemente desprovida e esvaziada de ideologia e do político, seu uso escolar guarda em si representações de mundo, expressa subjetividades, instila projetos realizados pela classe dominante.

Podemos, então, questionar o porquê dos mapas políticos aparecerem com tanta frequência no nosso imaginário sobre as aulas de Geografia. O que está representado no mapa político? Essa pergunta é enunciada nos exercícios que acompanham o mapa. A figura nos apresenta linhas sempre iguais separando polígonos de cores diferentes. Mas essa não é a resposta esperada. O mapa mostra países - certo!, se estivermos no ensino fundamental. Já no ensino médio, espera-se que sejam empregados os conceitos ensinados pela Geografia: o mapa político representa os territórios estatais, suas extensões e as fronteiras que as separam - certo! Contudo, já passamos no ensino básico, de modo que a nossa res- 
posta detecta o pressuposto limitador das visões que restringem a política sempre aos contornos do território estatal, baseando-se em um nacionalismo metodológico que nos cabe questionar.

A história da escolarização moderna nos alerta que uma das razões centrais da universalização da escola básica foi o fortalecimento dos projetos nacionais. O nacionalismo enforma o desenho curricular, especialmente no ensino de Línguas, de Literatura, de História e de Geografia, sempre distinguindo as comunidades nacionais. Poderíamos resumir as íntimas relações entre a escolarização e a nacionalização da população na expressão "escola-nação", geografia imaginada que nos ensigna de tal forma que, ainda que saibamos que a política não é feita apenas de superfícies rosas, verdes e lilases separadas por linhas pretas, recorremos a essa geometria simples sempre que queremos representar o mundo.

A escola tem tido um conjunto de atribuições essencial no bojo do processo de modernização dos Estados-Nação que despontaram a partir da queda do absolutismo no século XVIII, estendendo-se até a consolidação dos regimes democráticos no final do XIX e início do século XX, em um contexto histórico marcado por revoluções políticas e industriais. Da mesma forma, a escola tem sido um veículo para construir as nações nos processos de descolonização, cabendo aos sistemas educacionais, à escola, assegurar o desenvolvimento moral, cultural e político das novas nações. A intensa mobilidade das populações que migravam para as cidades, mas também daquelas que empreendiam movimentos interestatais e intercontinentais tinha que se submeter a uma educação nacional. A essa escola "nacionalizante" competia, naqueles tempos, um somatório de tarefas que cobrisse desde a assimilação das culturas dos imigrantes até a formação da identidade nacional, estimulando os valores patrióticos, passando pela promoção da doutrina religiosa oficial e pela transmissão da língua adotada como sendo a língua nacional.

A escolarização da sociedade foi um processo longo e diverso em inúmeras partes do globo, que culminou com a participação universal, inicialmente das crianças e, bem mais tarde, dos jovens secundaristas. $\mathrm{O}$ progressivo controle da educação pelo Estado foi determinante para a elaboração de normas que atendessem as mais variadas finalidades para o eficaz funcionamento dos siste- 
mas educativos. A escolaridade tornou-se obrigatória assim como a presença da escola em todo o território nacional, aí incluídas as regiões transfronteiriças. Nesse contexto, a escola, a educação é parte intrínseca de um projeto estatal, geopolítico, homogeneizador, como aponta Regina Coeli Machado e Silva no artigo aqui compartilhado, e será também parte de projetos de integração, como os apresentados neste livro por Sylvie Considère e Fabienne Leloup (entre França e Bélgica, no contexto da União Europeia).

Em que pese a relevância de disciplinas como História e Geografia nesse contexto nacionalista, a imposição de uma língua nacional guarda um forte nexo com a questão da escola de fronteira. À vista disto, se a modernidade representou uma ruptura com a sociedade de ordens da Idade Média, que negava o exercício das liberdades individuais, e passou a valorizar as grandes instituições coletivas, propiciando mudanças e intercâmbio social, cabe-nos refletir como a escola, na contemporaneidade, reencena princípios basilares da modernidade. Ao tomarmos como referência o ensino da língua, encontramos um exemplo acabado, pois como afirma Faraco, "a concepção normativa da língua é certamente uma das mais fortes e resistentes na história do pensamento ocidental." (1997, p. 53).

Esse modelo de educação universal e moderna, em pleno século XXI, ainda não se materializou neste país, e a permanência na escola ainda é um sério desafio para a sociedade brasileira e para muitas outras pelo mundo afora. De mais a mais, o alargamento dos sistemas de ensino, com a consequente ampliação do número de unidades escolares, e o maior acesso à escolarização criaram uma situação conflitante do ponto de vista linguístico no Brasil, e que pode ser rebatido para as escolas binacionais localizadas em regiões transfronteiriças, pois "passaram a frequentar a escola, em número significativo, falantes de variedades do português muito distantes do modelo tradicionalmente cultivado pela escola" (idem, p.57). Embora não queira isolar a questão da linguagem em relação aos problemas da escola, Faraco é incisivo: "Passou a haver um profundo choque entre modelos e valores escolares e a realidade dos falantes: choque entre a língua da maioria das crianças e o modelo artificial de língua cultuado pela edu- 
cação da linguística tradicional; choque entre a fala do professor e a norma escolar; entre a norma escolar e a norma real; entre a fala do professor e a fala dos alunos" (ibidem).

No nosso entender, a questão linguística exemplifica como o contexto fronteiriço coloca à escola o desafio de transgredir o formato disciplinar e parcelar, para revestir-se de um caráter interdisciplinar, multidisciplinar, capaz de assegurar a mútua cooperação entre as várias áreas. Da mesma forma, seja qual for a concepção a informar os colégios, outras escalas geográficas se fazem presentes nas salas de aula. O diálogo e a convivência na escola nos lembram de que esta é um território, inserido e contraditório a outros territórios. Com isso, queremos dizer que a condição geográfica de discentes e docentes se expressa nas relações pedagógicas - como fonte de conhecimentos comuns que dialogam com o currículo instituído; como origem de conflitos e questionamentos à norma ensinada, entre outras possibilidades. Queremos ainda dizer que os projetos de cada agente nesse espaço podem ser potencializados ou reprimidos ao encontrarem-se com os demais projetos. Quando os campos da experiência e do processo pedagógico se reforçam, um novo interesse é mobilizado nos professores e alunos, trazendo encantamento pelas aulas. Os conflitos gerados pela dissonância entre o vivido e o estudado causam sofrimento e, muitas vezes, o abandono da escola pelo aluno e/ou o desdém do aluno pela escola. Exemplos dos diferentes desfechos desses encontros são discutidos no artigo de Rosario Brochado.

As instituições de ensino em condição fronteiriça expressam ainda mais claramente esse processo. As fronteiras entre estados são lugares dissonantes à norma nacional. Nesta norma, as fronteiras são frequentemente representadas como fontes de penetração, de contágio, de práticas morais duvidosas ou simplesmente como vazios a serem colonizados pela nação. Mais frequentemente, os lugares de fronteira não são representados, ficando fora do horizonte imaginativo da escola-nação, ao mesmo tempo em que o limite aparece apenas como o ponto final do estado, como bem nos mostram Regina Coeli Machado e Silva e Etta Kralovec nos artigos incluídos neste volume. 
Como essas autoras mostram, nesse contexto de invisibilização, o ato pedagógico, ensinar e aprender na fronteira, requer um forte movimento na busca pelo sucesso, na atribuição de significados, no encontro com o prazer. Lecionar nessa perspectiva exige uma preparação diferenciada. Não são poucas as pessoas que, direta ou indiretamente, encontram-se comprometidas com processos de formação inicial e continuada de docentes e entregam-se a uma arquitetura de mundo em grau superior ao existente, como indicam Zuila Santos e Jorgelina Tallei, Laura Amato e José Lindomar Albuquerque em seus textos. Essa construção implica perseguir mais justiça, mais humanidade, mais fraternidade, mais solidariedade, mais igualdade, mais sustentabilidade. Por se tratar de valores que fazem parte dos ideários humanistas, necessitam ser espelhados ou projetados nas práticas docentes. Não deve significar, contudo, atribuir aos educadores responsabilidades fora de seu alcance e das suas atribuições profissionais. Mesmo porque, a educação por si só não será a solução para todas as mazelas que desde longa data afetam o cotidiano e o futuro de inúmeras localidades, particularmente as de fronteira. Ademais, apenas uma parte da educação das pessoas acontece na escola.

Isso posto, a presente obra é um convite à travessia das fronteiras disciplinares e das fronteiras políticas, uma reivindicação do direito de atravessamento postulado por Zuíla Santos, bem como por Tony Payan e Irasema Coronado aqui neste livro. Transpô-las não para apagá-las mas, sobretudo, para compreender aquilo que elas mesmas dizem separar. Trata-se, portanto, de uma viagem necessariamente densa, seja no tempo ou no espaço, visto abarcar realidades diversas, heranças há muito estabelecidas, memórias que não desaparecem. Até porque, a fronteira na contemporaneidade necessita de uma investigação da escuta, em que o conhecimento frio, aquele que se detém no âmbito das faculdades racionais seja transcendido por um conhecimento que conceba a todos como sujeitos. Considerando que não são poucos os sistemas de ensino seletivos e excludentes, a relação com o saber, a relação com a fronteira, demanda uma compreensão que, antes de tudo, reconheça a lógica da cosmovisão que os citadinos fronteiriços 
dela possuem, ou, nas palavras de Tallei, Amato e Albuquerque, pensar em outra fronteira, "un lugar transcultural" ou "el entre lugar". Desse entendimento depreende-se que aquilo que as crianças e os jovens ponderam a respeito do que têm que aprender implica em discutir não apenas seu protagonismo enquanto estudantes, mas também o de professores, socioeducadores, pedagogos entre tantos outros sujeitos envolvidos com as finalidades e os princípios referentes ao educar para a fronteira. Implica, também, em ter coragem para encarar os desafios, na expressão de Tal Yaar-Waisel, em sua contribuição sobre o ensino das fronteiras em Israel.

Ensinar e educar para a fronteira demanda reconhecer o trânsito de uma realidade ordenada, segura e elucidada, própria da modernidade, para a condição mutante, instável e ofuscada da ultramodernidade. Assim, é importante frisar que a fronteira é marcada por passagens, portanto por encontros, que enformam hibridismos e convergências de culturas (seguindo a pista que Edgar Garcia Velozo nos dá). E, assim sendo, a relação do sujeito com a fronteira demanda olhares que ultrapassem o âmbito da mistura, do conflito, da separação, da integração, do domínio, da subordinação. Seria permitido devanear acerca de uma escola transnacional em condição fronteiriça? Como aponta Kralovec, seria permitido devanear sobre estudantes fronteiriços como embaixadores dessa multiculturalidade? Nesses termos, poderia a escola incorporar ao seu projeto uma perspectiva que fosse para além do nacional, reconhecendo sua condição fronteiriça, de tal modo a construir e realizar um ensino "pós-nacional"? Não se trata de liquidar a ideia de Estado-Nação, mas de repensar o papel da escola na contemporaneidade, embora com certo atraso. Ou seja, idealizar uma escola "supranacional", tendo em vista que a relação do indivíduo com a fronteira e as sensações e percepções que emergem dos contatos vários estabelecidos com a estremadura podem fazer paralelo à construção de uma cidadania outra. Afinal, o alunado que circula nessa região possui um perfil próprio, de quem está inserido em uma realidade onde o local e o global se articulam em bases específicas e dinâmicas, processo que é bem apresentado pela contribuição de Chiara Brambilla a este livro, ao reivindicar o nascimento de uma cidadania mediterrânea e multisituada, que contém 
a superação dos limites impostos por fronteiras e nacionalismos.

Convém recordar que a escola produz cultura e no seu interior também circulam e coexistem diversas outras culturas, dentre as quais, as infantis e as juvenis, pois, como diz Escolano Benito, "la escuela ha sido y es un lugar de producción de cultura y esta cultura se objetiva en las prácticas en que se operativizan los procesos formativos" (2012, p. 12). A par dessa ideia, cumpre-nos interrogar acerca das práticas que se desenrolam em seu espaço, sejam elas referentes à materialidade escolar ou ao processo de escolarização, sem omitir os saberes por ela realizados. Contudo, não podemos perder de vista que a cultura escolar não é estável, tampouco desprovida de conflitos em sua elaboração (Vidal; Schwartz, 2010). Nessa perspectiva, o currículo - o programa das disciplinas escolares - demanda uma mirada minimamente atenta, visto que na proposição de projetos educativos emancipadores, voltados para a edificação de uma sociedade democrática e progressista, a seleção dos blocos de conteúdos culturais deve ser criteriosamente observada para que "melhor contribuam para uma socialização crítica dos indivíduos" (Torres Santomé, 2013, p. 156).

Ora, sabemos que existe uma dimensão educativa, ou melhor, formativa, ligada à fronteira, na qual esta é deslocada para o centro, atribuindo à problemática curricular um caráter multiescalar. A quem se destina a educação para a fronteira? Qual deve ser o seu alcance? A quem cabe definir os princípios e as políticas de um educar para a fronteira?

A realidade fronteiriça é pensada por governantes e planejadores, que ditam medidas que impactam o cotidiano da fronteira. Nessa perspectiva, as regiões fronteiriças são afetadas pelas dimensões da justiça, as quais se articulam, se imbricam, exaltando a complexidade do educar para a fronteira. Estamos fazendo referência à justiça social, à justiça espacial e à justiça escolar; e, portanto, ao direito de se ter direitos; à justiça muito mais como possibilidade de felicidade e bem estar do que qualquer forma de desgraça. Isso significa dizer que, em uma sociedade que se autoproclama ou se considera democrática, tanto os direitos como os deveres para todos têm que, necessariamente, estar normatizados, exarados e serem realizados. 
Assim posto, a educação formal, realizada nas escolas, e a informal, desenvolvida em outros espaços educativos e formativos, requer contextualização, sendo tomada na perspectiva do direito à cidade - expressão de Henri Lefebvre para reivindicar o direito coletivo de produzir espaços e construir territórios a partir de projetos de múltiplos atores (Lefebvre, 2009). Afinal, viver na cidade demanda uma série de serviços, desde educação e saneamento básico até habitação e saúde, além daqueles que possibilitam a mobilidade. Ocorre que esses serviços são direitos. Além desses, viver na cidade implica o direito de se manifestar, de se vestir, de se alimentar, de saciar o prazer pela cultura, pela diversão e pelo lazer. Nesse rol, não pode faltar o direito ao emprego, a uma atividade remuneratória. Está-se lidando, indiscutivelmente, com direitos humanos (Rodrigues, 2017). Por mais que as regiões fronteiriças sejam tomadas como "terras de ninguém”, estereotipadas pela mídia e imaginadas como espaços pertencentes ao submundo, apenas à primeira vista nos parecem isoladas e isoladoras. Trata-se de áreas urbanizadas, articuladas à lógica capitalista dominante. Por outro lado, isso não anula o fato de significarem realidades marcadas por suas especificidades, em que as escolas se territorializam e desempenham um papel peculiar, o que fica claro quando consideramos as escolas de fronteira em uma perspectiva socioespacial.

Empreender a leitura da escola nessa perspectiva nos faz retomar as relações que se instituíram entre o Estado e a educação. No Brasil, mas não apenas nele, é notória a centralização e a concentração administrativa da ação educativa. Trata-se, portanto, de relações verticalizadas, rigidamente hierarquizadas. O currículo enquanto elemento central da ação educacional tem sido, historicamente, imposto de cima. A aquisição de materiais didáticos e sua distribuição, dentre eles o livro didático, também espelham esse mecanismo centralizador, como discutido por Flaviana Gasparotti Nunes. Ocorre que essa forma de controle das ações secundariza excessivamente o papel do território no conjunto das experiências dos sujeitos envolvidos no processo educativo: alunos e profissionais da educação, além dos atores que compõem a comunidade escolar.

O entorno socioespacial da escola, a geografia de oportunidades nela instalada, constituem fatores da escala local que reper- 
cutem sobremaneira na construção das desigualdades de oportunidades, bem como das desigualdades escolares. É nesse território que são travadas relações sociais com forte grau de complexidade. Nos territórios onde a vulnerabilidade social é mais acentuada, onde as formas de segregação são ainda mais visíveis, onde a justiça social é mais precária, a escola representa o espaço em que um conjunto de tensões se manifesta e se atualiza e no qual a questão da justiça escolar adquire outros contornos. Ademais, em tais áreas são verificados casos improváveis de sucesso escolar, onde os frios números das estatísticas apontariam para o inverso, para o fracasso. Nessa perspectiva, a segregação socioespacial converte-se em um sério obstáculo às oportunidades educacionais, ou melhor, constitui-se em um sério promotor de injustiça, injustiça que se revela a um só tempo social e escolar. Se admitirmos que o entorno socioespacial dessas instituições escolares não se encontra dissociado do processo pelo qual resultou a organização e a estruturação desses territórios, então para o enfrentamento da questão educacional deve-se considerar a questão espacial. Melhor dizendo, é mister avaliar as consequências da organização espacial em termos de justiça social, bem como os desdobramentos desta na organização do espaço.

Configura-se assim uma relação dialógica, de tal modo que as interações entre justiça social e justiça espacial reclamam ser articuladas à justiça escolar. Bem sabemos que a educação por si só não é capaz de estancar os inúmeros problemas sociais, políticos, ambientais e culturais que afetam o cotidiano nas áreas periféricas. Sendo assim, a questão da justiça escolar demanda um enfrentamento em novas e desafiadoras bases, em um quadro onde as políticas públicas têm que se fazer presentes. Algumas dessas políticas são apresentadas por Eliana Sturza; Marcos Bohrer, Armindo Rockenbach e Nestor André Käercher; e Geiza Rorato, quando tematizam os projetos para escolas, institutos e universidades públicas nas fronteiras brasileiras.

A globalização e a instituição de novas tecnologias de transporte e comunicação, a exemplo da internet, pode impactar o ensino sobre a fronteira em escolas em contextos não-fronteiriços, como nos mostram os estudos de Francisco Lara-Valencia e Daniel Furnish aqui reunidos, e que trazem estratégias para problematizar tais visões estanques e homogeneizantes. Ao contrastar contextos 
fronteiriços distantes geográfica e socialmente, podemos produzir conhecimentos significativos sobre os territórios e desconstruir as imagens que reduzem as fronteiras a regiões securitizadas.

Todas essas preocupações e esperanças nos levaram a conceber este livro, Ensinando Fronteiras: projetos estatais, representações sociais e interculturalidade. Seu propósito e o público a que se destina espelham o encontro da fronteira com a educação em todos os níveis, desde a educação infantil até a pós-graduação. Os textos reunidos documentam a busca de alinhamentos para cultivar a esperança em tempos e espaços melhores de se viver, e demonstram a potência dos atributos da escola na direção do acolhimento, do cuidado e do crescimento intelectual e cidadão.

Esses e muitos outros questionamentos desencadearam a produção dos dezesseis textos que compõem o livro. Na sua produção, as autoras e os autores trilharam perspectivas teórico-metodológicas plurais e contemplaram temáticas diversas, sem perder de vista suas fronteiras, cujos significados são adquiridos pela cultura, pela experiência, pelo compartilhamento de projetos. Discutida em seus contextos educacionais, a fronteira funciona aqui como uma linha de pensamento que apresenta ao leitor as complexas e numerosas características da linha de fronteira pelo mundo. Aliado a isso, os movimentos migratórios se desvelam através dos textos, funcionando, também, como um enredo nessa história.

$\mathrm{Na}$ organização dos trabalhos, os textos foram agrupados em duas seções. A primeira apresenta a relação entre a força do Estado de agir sobre a realidade fronteiriça e as respostas e novos questionamentos dos grupos ali presentes. Nessa parte, as instituições de ensino localizadas na fronteira, com seus planos e projetos, derivados tanto da esfera nacional quanto da esfera local, são o foco principal. Em uma oposição dialética a isso, situam-se docentes e alunos - em sua maioria bilíngues e de distintas nacionalidades - que incorporam tais projetos, alterando-os e transformando-os conforme a realidade local. Realidade essa que também é estudada, visto que suas complexidades ajudam a formar novas soluções para o educar na fronteira.

$\mathrm{Na}$ segunda parte do livro, o aspecto institucional-estatal torna-se mais periférico, trazendo um novo foco para o leitor: as características sociais e culturais da realidade supracitada. Assim, 
discute-se a atuação de grupos e indivíduos na construção de suas identidades e a relação dessa construção com aspectos de ordem histórica e cultural. Além disso, as imagens têm um papel importante nessa construção, uma vez que o conteúdo de livros didáticos e a representação gráfica da fronteira por desenhos de alunos também nos mostram visões da realidade fronteiriça.

Ao longo dessas duas seções, percorre-se o mundo. São abordadas as fronteiras compartilhadas entre Brasil e Paraguai, Uruguai, Bolívia e Peru. Segue-se para a América do Norte, onde o encontro entre EUA e México é retratado. O cenário europeu-africano também faz parte dessa obra, assim como a região fronteiriça entre a França e Bélgica e as fronteiras de Israel (figura 1). Vemos a faixa de fronteira, limites, díades, regiões fronteiriças, cidades-gêmeas, cidades na fronteira e pequenos lugares diretamente ligados às vantagens da fronteira, evidenciando que o fenômeno fronteiriço assume diferentes implantações e instiga professores e pesquisadores em muitos lugares pelo mundo. Confessamos que tivemos dificuldade em enquadrar em polígonos e linhas - em um mapa político tradicional - os multiformes processos sociais em curso e nossa rica imaginação geográfica sobre os lugares de fronteira.

Nesse percurso, os movimentos migratórios através das fronteiras atuam como catalisadores, construindo inovações e respostas para o ensino nas e das fronteiras. O livro é apresentado, propositalmente, de maneira bilíngue, ilustrando a dinâmica linguística das fronteiras, tanto no seu bilinguismo quanto na vida proporcionada pelos dialetos locais.

A maioria dos textos é de autores brasileiros, em contatos realizados principalmente nos Seminários de Estudos Fronteiriços, promovido pelo Mestrado de Estudos Fronteiriços no campus Corumbá da Universidade Federal do Mato Grosso do Sul. As contribuições da comunidade internacional de Estudos Fronteiriços chegaram a nós principalmente através dos ricos diálogos possibilitados pelos eventos da Associação para os Estudos Fronteiriços (ou ABS, a Association for Borderland Studies). A construção de uma comunidade de interpretação sobre a fronteira está ainda em curso e esperamos contribuir ao tematizar aqui os diferentes aspectos ligados ao ensino em fronteiras. 
Figura 1 - Fronteiras discutidas neste livro

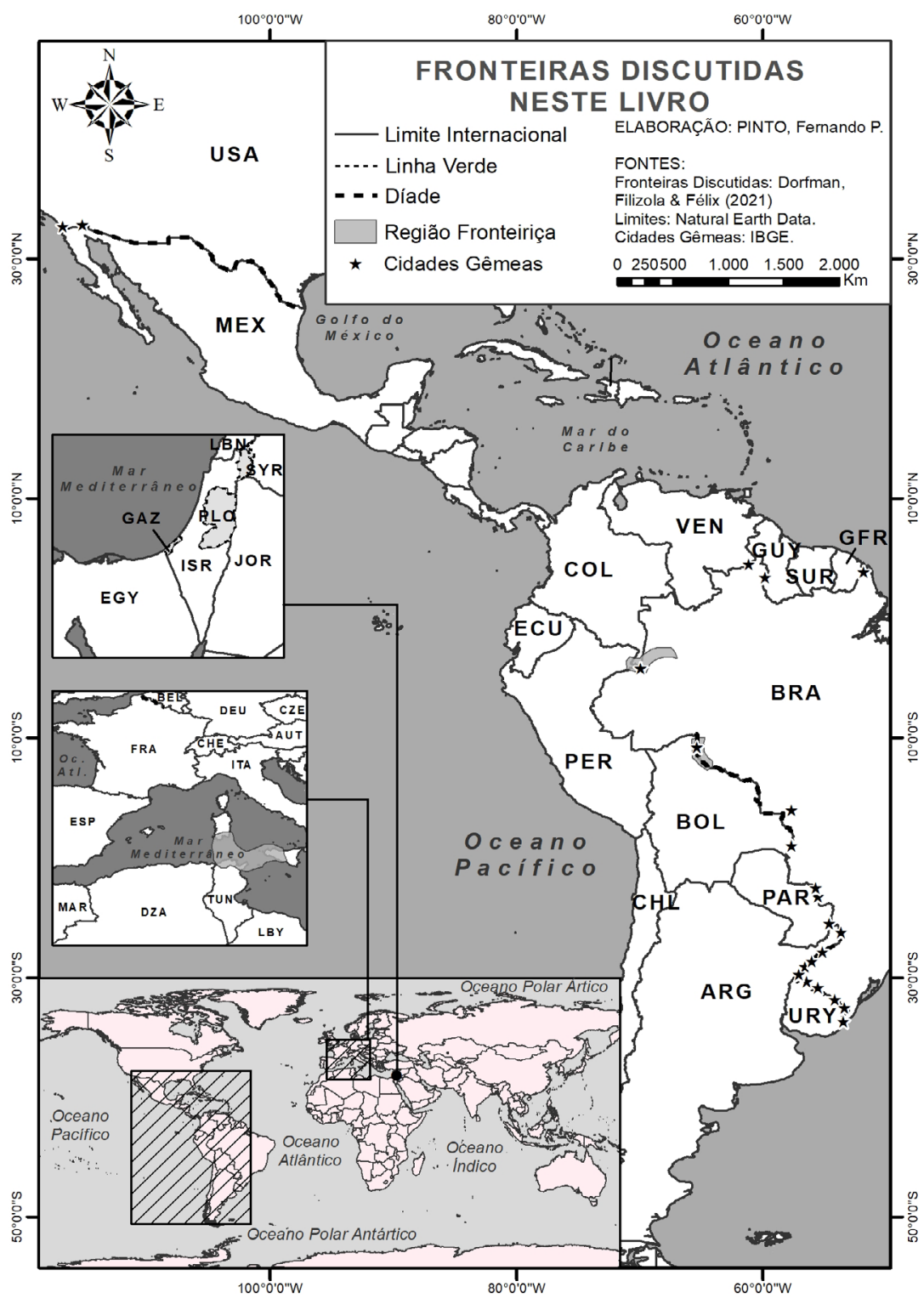

Fonte: Dorfman, Filizola e Félix. Elaboração: Fernando P. Pinto (2021) 
Agradecemos a todos os autores e autoras que, pacientemente, ajudaram a compor esta obra, respondendo de maneira solícita às nossas requisições, mesmo em meio a tantas dificuldades que nos têm apresentado a pandemia. Também gostaríamos de agradecer à cartografia realizada por Fernando P. Pires e a Mauro e Cecília Dorfman pela proposta de capa. Agradecemos à Dra. Walkiria Ayres Sidi e a Paulo Bunselmeyer Ferreira pela tradução cuidadosa de textos do inglês.

A colaboração com as professoras Dras. Patrícia Reuillard e Cláudia Mendonça Scheeren, das disciplinas de tradução do francês e do italiano dos cursos do Instituto de Letras da Universidade Federal do Rio Grande do Sul, tem permitido divulgar a vanguarda da pesquisa aos leitores brasileiros já há alguns anos. Agradecemos sua dedicação e abertura às nossas propostas, bem como aos seus alunos Clarice Campani Langer, Alex de Cassio, Anna Carolina Teles e Gilmar Taufer. Num contexto de amizade, agradecemos também à revisão atenta realizada por João Carlos Córdova Frasson, assim como a Vithor Amaral Prestes pelo apoio no tratamento das imagens, à Débora Mendes Pizzio pela colaboração na formatação dos artigos. À gráfica da UFRGS, na pessoa da Joseane Ranzonlin, pelo afeto e competência. E obrigado a Ronaldo Machado (Editora Letra1) e a Flávio Ilha (Editora Diadorim) pelos conselhos editoriais e pelo cuidado nesta edição.

Agradecemos à Dra. Cláudia Zeferino Pires e ao Dr. Paulo Roberto Rodrigues Soares, coordenadora e vice coordenador, a Pedro Henrique da Silva Heim, secretário, e a todos os técnicos e bolsistas que atuam no Programa de Pós-Gradução em Geografia da Universidade Federal do Rio Grande do Sul (POSGEA/UFRGS) por estarem sempre disponíveis a atender nossas solicitações. Por fim, agradecemos ao POSGEA, à UFRGS e à Coordenação de Aperfeiçoamento do Pessoal de Nível Superior (CAPES) pelo financiamento da obra e desejamos aos leitores que vejam este livro como uma contribuição a uma discussão que se faz em linguagem acadêmica, mas que diz respeito ao reconhecimento dos direitos de fronteiriços, de migrantes e da comunidade escolar, direitos humanos de passar ou de ficar, de participar na vida pública e na concretização de seu projetos coletivos. 


\section{Referências}

ESCOLANO BENITO, Augustín. Las materialidades de la escuela (a modo de prefacio). In: GASPAR DA SILVA, V. L.; PETRY, M. G. Objetos da escola: espaços e lugares de constituição de uma cultura material escolar (Santa Catarina - Séculos XIX e XX). Florianópolis: Insular, 2012. p. 11-18

FARACO, Carlos Alberto. Linguagem, escola e modernidade. In: LEFEBVRE, Henri. O direito à cidade. São Paulo: Centauro, 2009. GHIRALDELLI JÚNIOR, P. Infância, escola e modernidade. São Paulo: Cortez; Curitiba: Editora da UFPR, 1997. p.49-59

RODRIGUES, Rute Imanishi. O direito à cidade na academia e nas ruas. In: SANTOS JUNIOR, Orlando Alves dos et all. (orgs.) Políticas públicas e direito à cidade: programa interdisciplinar de formação de agentes sociais. Rio de Janeiro: Letra Capital, 2017. p. 34-39

SANTOS, Milton. A natureza do espaço: técnica e tempo, razão e emoção. São Paulo: HUCITEC, 1996.

TORRES SANTOMÉ, Jurjo. As culturas negadas e silenciadas no currículo. In: SILVA, T. T. (org.) Alienígenas na sala de aula: uma introdução aos estudos culturais em educação. 11. ed. Petrópolis: Vozes, 2013. p. 155-172

VIDAL, Diana Gonçalves; SCHWARTZ, Cleonara Maria. Sobre cultura escolar e história da educação: questões em debate. In: VIDAL, D.G; SCHWARTZ, C.M. (orgs.) História das culturas escolares no Brasil. Vitória: EDUFES, 2010. p. 13-35 